\title{
TRUMPAREGYSTE் VAIKŲ AMŽIUJE: EPIDEMIOLOGIJA, RIZIKOS VEIKSNIAI, GYDYMAS IR PROFILAKTIKA
}

\author{
Ignė Dumbliauskaitė, Sigitas Filipauskas, Gintarė Gečaitė \\ Lietuvos sveikatos mokslu universiteto Medicinos akademija, Medicinos fakultetas
}

Raktažodžiai: refrakcijos ydos, miopija, vaikai, epidemiologija, rizikos veiksniai, profilaktika, gydymas.

\begin{abstract}
Santrauka
Darbo tikslas - iqvertinti, susisteminti ir išanalizuoti mokslinejje literatūroje pateikiamus duomenis apie vaikų miopiją, jos epidemiologiją, rizikos veiksnius, gydymą bei profilaktiką. Šioje sisteminèje apžvalgoje išanalizuoti 25 viso teksto straipsniai. Remiantis atrinktų straipsnių rezultatų duomenimis, galime teigti, kad miopija gana plačiai paplitusi tarp paauglių, jos atsiradimą lemia ne tik aplinkos veiksniai, bet įtakos turi ir genetika. Miopijos korekcijai naudojami kontaktiniai lęšiai, akiniai išgaubtais stiklais, o retais atvejais - algoritmu kontroliuojami antimuskarininiai akių lašai.
\end{abstract}

\section{Ivadas}

Refrakcija yra šviesos spindulių lenkimas, jiems sklindant iš vienos skaidrios terpès ị kitą, esant skirtingam tankiui [1]. Refrakcijai ịtakos turi tokie akių parametrai, kaip ragenos kreivumas, priekinès kameros gylis, lęšio storis ir ašies ilgis [2]. Emetropijos atveju, t.y. akyje, kurioje nèra refrakcijos ydos, lygiagretūs šviesos spinduliai nuo objekto sklinda ị tinklainę, tad suvokiamas ryškus vaizdas [1]. Refrakcijos sutrikimas esti, kai vaizdas netiksliai fokusuojamas ị tinklainę. Yra trys refrakcijos ydų tipai: trumparegystè, toliaregystè ir astigmatizmas. Miopija (arba trumparegystè) atsiranda, kai akies refrakcijos jëga yra per stipri. Dažniausiai miopija išsivysto, kai akies ašies ilgis yra per ilgas, palyginti su ragenos ir lęšio lūžio jèga. Židinio taškas yra prieš tinklainę, o vaizdas, pasiekiantis tinklainę, neryškus. Skiriami trys trumparegystès laipsniai: nedidelio (iki -3D), vidutinio (nuo -3,25 iki -6D) ir didelio laipsnio trumparegystè (daugiau kaip -6D) [1,3-5]. Miopija yra labiausiai paplitusi suaugusiujų ir vaikų koreguojamo regejjimo sutrikimo priežastis ir pagrindinè besivystančių šalių gyventojų išvengiamo aklumo priežastis.
Maždaug kas šeštas pasaulio gyventojas yra trumparegis [6]. Miopijos vystymasis prasideda ankstyvajame amžiuje, jos dažnis ir sunkumas didèja nuo vaikystės ir paauglystès iki pilnametystès. Nustatyta, kad beveik 20 proc. vaikų iki vèlyvosios paauglystès atsiranda refrakcijos sutrikimų, dèl kurių reikalingi akiniai [1]. Šiame darbe aptariama viena iš refrakcijos ydu - miopija, jos paplitimas, rizikos veiksniai vaikų amžiuje, gydymas bei profilaktika.

Darbo tikslas - išanalizuoti ir aptarti ịrodymais pagristą informaciją apie vaikų miopiją, jos epidemiologiją, rizikos veiksnius, gydymą ir profilaktiką.

\section{Tyrimo medžiaga ir metodai}

Taikyta sisteminè mokslinès literatūros bei dokumentų apžvalga ir analizè. Duomenų buvo ieškoma PubMed, Google Scholar, Up ToDate, Wiley bei Cochrane duomenu bazèse. Visateksčiai straipsniai atrinkti, jei jų pavadinimas, santrauka ar reikšminiai žodžiai buvo tinkami šiai apžvalgai. Pasirinktos tik anglų kalba skelbtos publikacijos. Vartoti anksčiau nurodyti raktažodžiai. Atrinkti ir apibendrinti 25 straipsniai.

\section{Rezultatai}

Epidemiologija. Vaikų trumparegystès paplitimas didejja. Dažniausiai trumparegyste pasireiškia brendimo metu ir po jo, kai akis išgyvena paauglystès augimo fazę. JAV ikimokyklinio amžiaus vaikų trumparegystès paplitimas yra nuo 1 iki 5 procentų, mokyklinio amžiaus vaikų kone 9 procentai, o paauglių - apie 30 procentų $[1,3,4]$. Miopijos paplitimas skiriasi priklausomai nuo etninès grupès ir yra ypač didelis Rytų Azijos šalyse. Kinijos ir Taivano paauglių miopijos paplitimas yra nuo 70 iki 85 procentu $[7,8]$. Tarp JAV mokyklinio amžiaus vaikų trumparegystè labiausiai paplitusi azijiečių (18,5 proc.) ir ispanų vaikams (13,2 proc.) [5]. Didelio laipsnio trumparegyste pasireiškia iki 20 proc. Rytų Azijos vidurinių mokyklų vaikų ir yra susijusi su negrịžtamomis regèjimo patologijomis. Europos baltujų rasès 
populiacijose trumparegystė paplitusi santykinai nedaug, ja serga maždaug 3-5 proc. $10-12$ metų ir iki 20 proc. $12-$ 13 metų vaikų [7]. Vokietijoje nustatytas trumparegystès paplitimas 3-17 metų amžiaus grupeje siekia 13,3 procento [9]. Lietuvos higienos instituto 2019 metų duomenimis, Lietuvoje miopiją turi daugiau nei 31 tūkstantis vaikų (nuo 1 iki 18 metų) [10].

Rizikos veiksniai. Trumparegystės tyrejjai Singapūre pranešè, kad paaugliai, skaitantieji ir rašantieji daugiau nei 20,5 val. per savaitę, turi daug didesnę tikimybę susirgti trumparegyste [11]. Etninè priklausomybè taip pat vertinama kaip paplitimo progresavimo tarp Azijos gyventoju rizikos veiksnys. Tarptautiniu mastu pranešama, kad Singapūre metinis trumparegystės progresavimo laipsnis yra $-0,80$ dioptrijų per metus [12], o Europos etninių grupių šis rodiklis artimas $-0,50$ dioptriju per metus [13]. Nors trumparegystė labai priklauso nuo aplinkos veiksnių, žinoma, kad ši regèjimo patologija pasireiškia šeimose, o tai rodo genetinị polinkị. Refrakcijos ydų paveldimumas, naudojant sferinị ekvivalentą kaip kiekybinị požymį, buvo nustatytas daugelyje šeimų ir dvynių tyrimų [14]. Ivertinimai, gauti remiantis tyrimais: paveldimumas imanomas nuo 15 iki 98 proc., tačiau svarbu pažymèti, kad refrakcijos ydų pagrindinè priežastis nebūtinai yra genetinè. Šeimos klasterị gali nulemti ir kiti veiksniai [14].

\section{Gydymas}

Optinė terapija. Akis gali automatiškai reguliuoti savo refrakciją ir ašies ilgị, kad sufokusuotų vaizdą i tinklainę. Jei akis pirmiausia negali pakoreguoti lūžio, ji gali pailgèti, kad išlaikytų fokusavimą. Bifokaliniai (progresiniai) lęšiai gali teikti aiškų vaizdą skirtinguose taškuose, teoriškai mažindami akies poreikị pailgèti. Daugelyje apžvelgtų tyrimų nustatyta, kad progresiniai lęšiai turi mažai reikšmingų ar nereikšmingų tendencijų, lètinančių progresą [15]. Palyginus su vieno regejjimo lęšiais, bifokaliniai ar multifokaliniai lęšiai lètina trumparegystės progresavimą, tačiau progresavimo laipsnio skirtumas paprastai nèra kliniškai reikšmingas [16]. Ortokeratologija yra ragenos lūžio terapija, kurios metu ragena pertvarkoma specialiai pagamintu kietu kontaktiniu lęšiu, stengiantis laikinai išlyginti jos kreivumą, taip sumažinant ragenos optinę galią ir fokusuojant vaizdą ị tinklainę. Šie lęšiai naudojami naktį, o dieną išimami [17]. Pagrindinès šios terapijos komplikacijos yra pakitęs ir netaisyklingas ragenos epitelis, ragenos uždegimas ir lęšiu netoleravimas. Amerikos oftalmologijos akademijos ataskaita nustate įvairias regejimo komplikacijas, susijusias su ortokeratologija, iskaitant daugiau nei 100 ragenos infekcijos atvejų [18]. Dienos metu dèvimi, deramai orui pralaidūs kontaktiniai lęšiai sulètino trumparegystès progresavimą ankstyvųų ty- rimų metu. Atsitiktinių imčių klinikiniai tyrimai parodè, kad dujoms laidūs kontaktiniai lęšiai neslopina akies augimo [19, 20]. Nors J. Walline ir kt. pranešè, kad mažiau trumparegystė progresavo dujoms laidžių kontaktinių lęšių grupeje, tyrejjai nerado akių augimo skirtumo. Buvo nustatyta, kad ragenos kreivumo pokyčiai laikini, tad trumparegystès progresavimo lètėjimas greičiausiai nebus nuolatinis, todèl vaikams neturètų būti rekomenduojami dujoms laidūs kontaktiniai lęšiai, vien tik norint sulètinti trumparegystès progresavimą [19].

Farmakologinis gydymas. Aktualūs farmacijos metodai trumparegystès progresavimui kontroliuoti yra antimuskarininiai akių lašai, vartojami ịprastinèje akių priežiūroje, siekiant išplèsti vyzdị ir sumažinti ar panaikinti akomodaciją. Atropinas yra plataus spektro antimuskarininis preparatas, kurio šalutinis poveikis yra laikinas jautrumas šviesai ir neaiškus matymas iš arti. Pirenzepinas veikia tik M1 antimuskarininius receptorius, kurių rainelèje susitelkia nedaug, todèl neišplečia vyzdžio ar sumažina akomodaciją tiek, kiek atropinas [21]. Vietinio veikimo vaistai nedažnai vartojami dèl šalutinio poveikio, pirmiausia dèl fotofobijos ir sumažejusio artimo regèjimo bei akomodacijos galimybių, tačiau trumparegystė gali būti kontroliuojama taikant mažesnes, algoritmais pagrịstas koncentracijas, tuo sumažinant šalutini poveiki [22].

Profilaktika. Apsaugantis veiklos lauko aplinkoje poveikis buvo ịrodytas atliekant daugelį epidemiologinių tyrimų. Guangzhou (Kinija) randomizuotas tyrimas ivertino 3 metu laikotarpio 952 6-7 metų vaikų papildomos kasdienės lauko veiklos aktyvumo efektyvumą. Tyrime intervencinè grupé buvo lyginama su kontroline tokio pat amžiaus vaikų grupe ( $\mathrm{n}=951$ ), esant ịprastiniam lauko veiklos aktyvumui. Intervencinè grupé parodè sferinès ekvivalentinès refrakcijos (trumparegystès poslinkio) sumažèjimą, palyginti su kontroline grupe (atitinkamai -1,42 D ir -1,59 D; atitinkamai 0,17 D [95\% PI, 0,01 D iki 0,33 D] skirtumas), $p=0,04$. Šiame tyrime padidejjęs aktyvumas lauke lèmè trumparegystès dažnio sumažejimą intervencinèje grupeje 23 procentais [23]. Tyrimai rodo, kad lauko užsiëmimai turi didesnị poveiki trumparegystės atsiradimo sumažinimui, o ne ligos progresavimo lètinimui [24]. J. Sherwin ir kt. atliko metaanalizę apibendrinti paskelbtas ataskaitas apie lauko veiklos laiko ir trumparegystės ryši jaunesniems nei 20 metų asmenims. Rezultatai patvirtino, kad ilgèjant lauke praleistam laikotarpiui, mažèja trumparegystès rizika. Surinkta informacija parodé, kad kasdien papildomai lauke praleista valanda per savaitę trumparegystès tikimybę gali sumažinti 2 procentais. Tai skatina praktinès trumparegystès prevencijos intervencijas ir suteikia daugelị kitų privalumų, susijusių su veikla lauke [25]. 


\section{Išvados}

1. Palyginus vieno regèjimo lęšius su bifokaliniais ar multifokaliniais, trumparegystės progresavimo laipsnio skirtumas dažniausiai nebuvo kliniškai reikšmingas.

2. Vaikams neturètų būti rekomenduojami kontaktiniai lęšiai vien tik norint sulètinti trumparegystès progresavimą.

3. Tyrimai parodè, kad lauko užsièmimai turi svarbų poveikị trumparegystès atsiradimo mažinimui ir ligos progresavimo letinimui.

4. Pastebėjome, kad trumparegystès paplitimas didèja, didejjant vaikų amžiui.

\section{Literatūra}

1. Coats DK, Paysse EA. Refractive errors in children. Up ToDate, 2019.

2. Flitcroft DI. Emmetropisation and the aetiology of refractive errors. Eye (Lond) 2014;28(2):169-179.

https://doi.org/10.1038/eye.2013.276

3. Giordano L, Friedman DS, Repka MX, Katz J, Ibironke J, Hawes P, Tielsch JM. Prevalence of refractive error among preschool children in an urban population: the Baltimore pediatric eye disease study. Ophthalmology 2009;116(4):739.

https://doi.org/10.1016/j.ophtha.2008.12.030

4. Vitale S, Sperduto RD, Ferris FL. Increased prevalence of myopia in the United States between 1971-1972 and 1999-2004. Arch Ophthalmol 2009;127(12):1632.

https://doi.org/10.1001/archophthalmol.2009.303

5. Kleinstein RN, Jones LA, Hullett S, Kwon S, Lee RJ, Friedman NE, Manny RE, Mutti DO, Yu JA, Zadnik K. Collaborative longitudinal evaluation of ethnicity and refractive error study group. Refractive error and ethnicity in children. Arch Ophthalmol 2003;121(8):1141.

https://doi.org/10.1001/archopht.121.8.1141

6. Wu PC, Huang HM, Yu HJ, Fang PC, Chen CT. Epidemiology of myopia. Asia Pac J Ophthalmol 2016;5(6):386-393. https://doi.org/10.1097/APO.0000000000000236

7. Rudnicka AR, Kapetanakis VV, Wathern AK, Logan NS, Gilmartin B, Whincup PH, Cook DG, Owen CG. Global variations and time trends in the prevalence of childhood myopia, a systematic review and quantitative meta-analysis: implications for aetiology and early prevention. Br J Ophthalmol 2016;100(7):882. https://doi.org/10.1136/bjophthalmol-2015-307724

8. Li SM, Li SY, Liu LR, Zhou YH, Yang Z, Kang MT, Li H, Yang XY, Wang YP, Zhan SY, Mitchell P, Wang N, Atchison DA; Anyang childhood eye study group. Peripheral refraction in 7and 14-year-old children in central China: the anyang childhood eye study. Br J Ophthalmol 2015;99(5):674-9.

https://doi.org/10.1136/bjophthalmol-2014-305322

9. Schuster A, Elflein H, Pokora R, Urschitz M. Prävalenz und Risikofaktoren der Kurzsichtigkeit bei Kindern und Jugendlichen in Deutschland - Ergebnisse der KiGGS-Studie. Klinische
Pädiatrie 2017;229(04),234-240.

https://doi.org/10.1055/s-0043-102938

10. Sveikatos statistika. Traumų ir nelaimingų atsitikimų stebėsenos sistemos duomenys. Higienos institutas, 2018.

https://stat.hi.lt/default.aspx?report_id=169

11. Quek TP, Chua CG, Chong CS, Chong JH, Hey HW, Lee J, Lim YF, Saw SM. Prevalence of refractive errors in teenage high school students in Singapore. Ophthalmic Physiol Opt 2004;24:47-55.

https://doi.org/10.1046/j.1475-1313.2003.00166.x

12. Saw SM, Tong L, Chua WH, Chia KS, Koh D, Tan DT, Katz $\mathrm{J}$. Incidence and progression of myopia in Singaporean school children. Invest Ophthalmol Vis Sci 2005;46(1):51-7.

https://doi.org/10.1167/iovs.04-0565

13. Donovan L, Sankaridurg P, Ho A, Naduvilath T, Smith EL, Holden BA. Myopia progression rates in urban children wearing single-vision spectacles. Optom Vis Sci 2012;89(1):27-32. https://doi.org/10.1097/OPX.0b013e3182357f79

14. Tedja MS, Haarman AEG, Meester-Smoor MA, et al. IMI - Myopia genetics report. Invest Ophthalmol Vis Sci 2019;60(3):M89-M105.

https://doi.org/10.1167/iovs.18-25965

15. Leo SW, Young TL. An evidence-based update on myopia and interventions to retard its progression. J AAPOS 2011;15(2):181-9.

https://doi.org/10.1016/j.jaapos.2010.09.020

16. Berntsen DA, Sinnott LT, Mutti DO, Zadnik K. A randomized trial using progressive addition lenses to evaluate theories of myopia progression in children with a high lag of accommodation. Invest Ophthalmol Vis Sci 2012;53(2):640-649.

https://doi.org/10.1167/iovs.11-7769

17. Charm J, Cho P. High myopia-partial reduction ortho-k: a 2-year randomized study. Optom Vis Sci 2013;90(6):530-9.

https://doi.org/10.1097/OPX.0b013e318293657d

18. Van Meter WS, Musch DC, Jacobs DS, Kaufman SC, Reinhart WJ, Udell IJ; American academy of ophthalmology. Safety of overnight orthokeratology for myopia: a report by the American academy of ophthalmology. Ophthalmology 2008;115(12):2301-2313e1.

https://doi.org/10.1016/j.ophtha.2008.06.034

19. Walline JJ, Jones LA, Mutti DO, Zadnik K. A randomized trial of the effects of rigid contact lenses on myopia progression. Arch Ophthalmol 2004;122(12):1760-1766.

https://doi.org/10.1001/archopht.122.12.1760

20. Katz J, Schein OD, Levy B, et al. A randomized trial of rigid gas permeable contact lenses to reduce progression of children's myopia. Am J Ophthalmol 2003;136(1):82-90.

https://doi.org/10.1016/S0002-9394(03)00106-5

21. Smith MJ, Walline JJ. Controlling myopia progression in children and adolescents. Adolesc Health Med Ther 2015; 6:133-140. 
https://doi.org/10.2147/AHMT.S55834

22. Wu PC, Yang YH, Fang PC. The long-term results of using low-concentration atropine eye drops for controlling myopia progression in schoolchildren. J Ocul Pharmacol Ther 2011;27(5):461-466.

https://doi.org/10.1089/jop.2011.0027

23. He M, Xiang F, Zeng Y, Mai J, Chen Q, Zhang J, Smith W, Rose K, Morgan IG. Effect of time spent outdoors at school on the development of myopia among children in China: a randomized clinical trial. JAMA J Am MedAssoc 2015;314:1142-1148. https://doi.org/10.1001/jama.2015.10803

24. Vagge A, FerroDesideri L, Nucci P, Serafino M, Giannaccare G, Traverso CE. Prevention of progression in myopia: a systematic review. Diseases 2018;6(4):92.

https://doi.org/10.3390/diseases6040092

25. Sherwin JC, Reacher MH, Keogh RH, Khawaja AP, Mackey DA, Foster PJ. The association between time spent outdoors and myopia in children and adolescents: a systematic review and meta-analysis. Ophthalmology 2012;119(10):2141-51. https://doi.org/10.1016/j.ophtha.2012.04.020

\section{MYOPIA IN CHILDREN: EPIDEMIOLOGY, RISK FACTORS, TREATMENT AND PREVENTION \\ I. Dumbliauskaitė, S. Filipauskas, G. Gečaitė}

Keywords: refractive errors, myopia, children, epidemiology, risk factors, prevention, treatment.

\section{Summary}

The aim of this work was to evaluate, systematize and analyze the data presented in the scientific literature on pediatric myopia, its epidemiology, risk factors, treatment and prevention.This systematic review analyzes 25 full-text articles. Based on the results of selected articles, we can state that myopia is quite widespread among adolescents, its occurrence is caused not only by environmental factors, but also by genetics.Contact lenses, convex glasses and, in rare cases, algorithmically controlled antimuscarinic eye drops are used for its correction.

Conclusions. When comparing single-vision lenses with bifocal or multifocal lenses, the difference in the degree of progression is usually not clinically significant.Contact lenses should not be recommended for children solely to slow the progression of myopia.Studies show that outdoor activities have an important effect in reducing the onset of myopia but slowing the progression of the disease. We have noticed that the prevalence of myopia also increases with age in children.

Correspondence to: igne.dumbliauskaite@stud.lsmu.lt

Gauta 2020-04-28 